\title{
JARID ARRAES E A POÉTICA DE RESISTÊNCIA
}

\author{
Níncia Cecília Ribas Borges Teixeira \\ Pós-doutora em Letras pela Universidade Federal do Rio de Janeiro (UFRJ) \\ Professora Associada da Universidade Estadual do Centro-Oeste (UNICENTRO-PR) \\ ninciaborgesteixeira@yahoo.com.br
}

\section{RESUMO}

Quanto mais plural for a perspectiva lançada sobre os meios de aquisição de conhecimento, maiores são as possibilidades de compreender as trocas simbólicas que constituem os discursos. Dessa forma, pensamos o espaço da literatura como possibilidade de representações simbólicas que também (re)produzem práticas culturais. História e Literatura são formas distintas, porém próximas, de dizer a realidade e de the atribuir/desvelar sentidos. Este confronto pode partir da natureza epistemológica, ou seja, o que se refere a uma reorientação dos paradigmas explicativos da realidade, que dão entrada em cena, no terreno da História, ao introduzir novos referenciais que a aproximam da literatura. Referimo-nos, por exemplo, à concepção de que a História, tal como a Literatura, é uma narrativa que constrói um enredo e desvenda uma trama. Este trabalho analisa o diálogo entre Literatura e História a partir da escrita da brasileira Jarid Arraes. A obra de Arraes recupera fatos históricos e os reelabora por meio da literatura, que possibilita percorrer os espaços de sombra, engendrados por uma História que os silenciou. Utilizamos, além de pressupostos teóricos que versam sobre o tema, dois textos da poeta para verificar de que forma a literatura torna-se um importante registro sobre a questão étnico-racial a partir do olhar de quem, por muito tempo, ficou relegado ao esquecimento, e, quando retratado, pelo viés literário, foi de forma estereotipada.

Palavras-chave: literatura, história, Jarid Arraes.

\section{ABSTRACT}

The paper analyzes the dialogue between Literature and History from the writing of Jarid Arraes. The poetry of Arraes recovers historical facts and reelaborates them through the literature that allows to cross the spaces of shadow, engendered by a History that has silenced them. Therefore, in addition to theoretical assumptions on the subject, we discuss two texts of the poet in order to verify how literature becomes an important record on the ethnic-racial issue from the look of who, for a long time, remained Relegated to oblivion, and, when portrayed by the hegemonic literary bias, sometimes was stereotyped.

Keywords: literature, history, Jarid Arraes. 


\section{Diálogos pertinentes: literatura e história}

"O texto literário como documento da história ou a história como contexto que atribui significado ao texto literário são caminhos que podem colidir no congestionamento da mão única por onde enveredam."

(MALLARD, 1995, p. 21)

Será que constituímos os discursos ou os discursos nos constituem? A dominação simbólica é também dominação política? Começar com perguntas no lugar de afirmações conduz o pensamento a navegar por novas possibilidades de representar o mundo, de pensar suas práticas e relações sociais. Enquanto sujeitos simbólicos, que se constituem pela e na língua, mas, também, nos silêncios fundadores e políticos dessa língua, lançamos nossa pesquisa sobre as possibilidades representativas dos indivíduos que são $o$ outro do discurso hegemônico.

Dessa forma, quanto mais plural for a perspectiva lançada sobre os meios de aquisição de conhecimento, maiores são as possibilidades de aprimorar a maneira de ver, compreender, interagir com as trocas simbólicas que constituem os discursos na atualidade; evitando a articulação de mais discursos que recaiam no reducionismo. Dessa forma, pensamos o espaço da literatura como possibilidade de representações simbólicas que também (re)produzem práticas culturais.

De acordo com Pesavento (2006), História e Literatura são formas distintas, porém próximas, de dizer a realidade e de lhe atribuir/desvelar sentidos, e hoje se pode dizer que estão mais próximas do que nunca. Este confronto pode partir de dois planos distintos. O primeiro deles seria de natureza epistemológica, dizendo respeito a uma reorientação dos paradigmas explicativos da realidade, que dão entrada em cena, no 
terreno da História, introduzindo novos referenciais que a aproximam da literatura. Referimo-nos, por exemplo, à concepção de que a História, tal como a Literatura, é uma narrativa que constrói um enredo e desvenda uma trama.

Pesavento (2006) afirma que

representar é, pois, fundamentalmente, estar no lugar de, é presentificação de um ausente; é um apresentar de novo, que dá a ver uma ausência. A ideia central é, pois, a da substituição, que recoloca 'uma ausência e torna sensível uma presença' (PESAVENTO, 2003, p. 40).

A narrativa historiográfica é uma construção intertextual acerca de um fato passado e tem como finalidade a possibilidade de verificação dos vestígios, evidências extraídas das fontes que relatam o fato histórico.

A História é uma urdidura discursiva de ações encadeadas que, por meio da linguagem e de artifícios retóricos, constrói significados no tempo. No caso, este entendimento da História como uma narrativa sobre o passado liga-se ao conceito da representação, que encarna a ideia de uma substituição, ou ainda da presentificação de uma ausência. Assim, no sistema de representações sociais construídas pelos homens para atribuir significado ao mundo, ao que se dá o nome de imaginário, a Literatura e a História teriam o seu lugar como formas ou modalidades discursivas que têm sempre como referência o real, mesmo que seja para negá-lo, ultrapassá-lo ou transfigurá-lo.

Quando a História fica relegada ao espaço de cientificidade, lugar onde reina um ideal de objetividade e verdade, é excluído qualquer direito à incerteza. Nesse caso, criase à volta da História uma aura de objetividade que legitima as informações que ali estão colocadas como referências irrefutáveis da realidade, o que, por sua vez, mascara o 
caráter ambivalente da linguagem e do trabalho seletivo do historiador: “[...] o historiador deve interrogar, investigar e auscultar o passado de várias maneiras, desconfiando das "lições" que a história edificante tenta nos passar como verdades absolutas" (LEONARDI, 1999, p. 115).

Nesse sentido, torna-se a literatura um espaço propício para a combinação entre história documentada e livre invenção ficcional, numa (re)construção de representações de mulheres. Além de observarmos que o caráter de verossimilhança da narrativa, bem como, o "encontro oblíquo entre ficção e verdade" colabora para o reforço dos aspectos críticos das representações ficcionais.

Para Luiz Costa Lima (2006), História e Ficção são indiscutivelmente intercambiáveis por utilizarem como base comum a linguagem, sendo, portanto, construções discursivas. O que o trabalho de Luiz Costa Lima (2006) ressalta é que durante todo o percurso entre a antiguidade greco-romana e a modernidade está marcada pelo conflito indissolúvel entre a independência e interdependência entre os conceitos, observando como as fronteiras são confusas e imprecisas. Talvez, por isso, seu texto se constrói no deslizamento entre esses conceitos, no relevo da possível contaminação entre ambos. Em relação à diferença da verdade na História e na ficção, Luiz Costa Lima ressalta

A verdade da história sempre mantém um lado escuro, não indagado. A ficção, suspendendo a indagação da verdade, se isenta de mentir. Mas não suspende sua indagação da verdade. Mas a verdade agora não se pode entender como 'concordância'. A ficção procura a verdade de modo oblíquo, i.e., sem respeitar o que, para o historiador, se distingue como claro ou escuro. Procurar captá-la por um instrumental historiográfico pode ser um meio auxiliar de explicá-la. Mas tão só (2006, p. 156). 
Luiz Costa Lima (2008) assevera sobre a predominância do emprego, na cultura ocidental, do termo fictio no sentido de mentira, fraude. Faz-se importante lembrar que o latim clássico, apesar de entender o termo, tanto em seu caráter de invenção/criação como no sentido de mentira, empregava com recorrência o sentido de fraude. Para o autor, isso se deve a dois fatores. Primeiro, a sobreposição da poética à retórica, que acaba reduzindo a reflexão desenvolvida por Aristóteles (1992), na Poética, e passa a encarar a linguagem em sua relação com o convencimento, à sedução.

O segundo momento refere-se à influência do cristianismo e sua visão monoteísta, de um Deus que é símbolo da criação, da origem. Nesse sentido, a ficção não deveria se igualar à criação, para, assim, não se igualar ao poder de Deus. Para o autor, a ficção é um conceito tão amplo que se estende desde o campo artístico até o campo do direito, das leis, da vida cotidiana. Ressaltando a possibilidade transgressora da ficção literária - de inverter por meio de suas representações a ordem e poder estabelecido -, Lima (2006) trabalha, de algum modo, com a verdade, posto que "O mundo da ficção é um mundo do faz-de-conta, ainda que sério. Essa seriedade faz com que ela se cruze, em seu caminho, com a verdade e/ou que se desnude a si mesma, que se declare ficção" (LIMA, 2006, p. 175).

Segundo Sandra Jatahy Pesavento (2006), o historiador está preso tanto à condição do real acontecido como às fontes e documentos referentes a esse real. Ou seja, o historiador não está livre para criar - em sentido absoluto -, mas, sim, para atribuir significados, no intuito de aproximar-se ao máximo do acontecido, valendo-se, para isso, do uso de métodos (testagem, comparação, cruzamentos) como comprovação.

No entanto, o que fica claro na visão pós-estruturalista da linguagem é que, independentemente da existência e utilização de métodos norteadores, a História e a 
Literatura necessitam do material concreto, que é a escrita, e nisso residem seus limites e o questionamento do estatuto de cientificidade da História, impossibilitando a existência da objetividade plena.

Assim, literatura e história são narrativas que tem o real como referente, para confirmá-lo ou negá-lo, construindo sobre ele outra versão [...] Como narrativas, são representações que se referem à vida e que a explicam (PESAVENTO, 2006, p. 3).

Notamos, portanto, que as fronteiras que delimitam o gênero histórico e o literário tornaram-se mais permeáveis no momento em que a História passou a ser vista, por muitos estudiosos, como um discurso de ficcionalização da realidade, assim como propôs Hayden White em trabalhos como Meta-História: a imaginação histórica do século XIX (2008) e Trópicos do Discurso: ensaios sobre a crítica da cultura (2001), que aplicam ao estudo de narrativas históricas conceitos da teoria literária, aproximando as práticas do escritor ficcionista à do historiador. Na perspectiva de Michel de Certeau, a escrita historiográfica configura-se como um espaço onde estão presentes

[...] relações entre um lugar (um recrutamento, um meio, um ofício, etc.), procedimentos de análise (uma disciplina) e a construção de um texto (literatura). É admitir que ela faz parte da 'realidade' da qual trata, e que essa realidade pode ser apropriada 'enquanto atividade humana, 'enquanto prática. Nessa perspectiva, gostaria de mostrar que a operação histórica se refere à combinação de um lugar social, de práticas 'científicas' e de uma escrita (CERTEAU, 2006, p. 66).

\section{Jarid Arraes: poética de resistência e empoderamento}


"Escrevo para honrar minha ancestralidade" JARID ARRAES

Nascida em Juazeiro do Norte, na região do Cariri (CE), em 12 de fevereiro de 1991, Jarid Arraes é escritora, cordelista e autora do livro As Lendas de Dandara. Vive em São Paulo (SP), onde criou a Terapia Escrita, media o Clube da Escrita Para Mulheres e o Clube Leitura Independente. Até o momento, tem mais de 60 títulos publicados em Literatura de Cordel, incluindo a coleção Heroínas Negras na História do Brasil e publicações em parceria com a Artigo 19 e o Think Olga.

Jarid Arraes é, atualmente, uma das mais representativas escritoras da internet, escrevendo textos críticos em defesa dos direitos humanos, com total atenção às mulheres, à diversidade sexual/gênero e questões raciais. A autora escreve cordéis, herança paterna. Depois de seu primeiro cordel, Dora, A Negra e Feminista, muitos outros foram escritos. Ela conta a história de mulheres negras que os livros fizeram questão de não contemplar. Arraes recebe isso como sua missão: faz do cordel não apenas um importante documento para promoção da cultura afro-brasileira, bem como uma ferramenta indispensável para o ensino em casa e nas escolas.

A escritora, em entrevista, explica sua gênese literária:

Desde muito nova eu sempre quis ser escritora, mas não entendia que aquilo era uma profissão, o que acabou acontecendo mesmo pelo destino, como se tivesse que acontecer. Eu comecei a escrever no meu blog sobre feminismo, depois fui convidada pela Revista Fórum e aí quando eu comecei a escrever os cordéis que eu de repente me dei conta: eu sempre quis ser escritora e agora eu sou escritora, socorro! (LIMA, 2015). 
Por meio da escrita, Arraes se descobre como mulher negra e como feminista. Isso, segundo ela, "a ajudou a entender o seu papel no mundo". Por meio da rima e da cultura popular, consegue naturalizar temas ainda tabus, como o racismo, a homossexualidade e a violência contra mulheres. Filha e neta de cordelistas, Jarid mantém viva a tradição que marcou sua infância, mas dá ao cordel um tom a ele pouco associado: de luta e engajamento político.

A Literatura, na perspectiva cultural, assim como a História, é espaço de discursos transgressores, com potencial de produzir interrogações, deslocamentos e rupturas nas categorizações naturalizadas. Nesse sentido, segundo Michel Foucault (2007), reside a necessidade do olhar crítico e desconstrutor que devemos direcionar à realidade, aos discursos e às verdades enquadradas na lógica do cogito cartesiano - que colocou o homem no centro do conhecimento e da razão e criou a ideia do sujeito universal -, para pensar o homem como objeto de conhecimento, que está inserido dentro de estruturas sociais, linguísticas, econômicas que o limitam e influenciam, extrapolando os limites da consciência. Na poética da Jarid Arraes, o discurso transgressor é evidenciado pelo tom de resistência e preservação da memória advindo da escrita que se desloca no tempo e no espaço.

No poema "Origem", escrito por Arraes, observa-se o registro de uma escrita centrada na subjetividade, em memórias que se entrelaçam com histórias da negritude e também com lacunas de ancestralidade, em que ela descreve os antepassados que não conheceu, as raízes apagadas, desafiando visões estereotipadas no que se refere à representação dos personagens negros: 
Não conheço minha história / Tão bem quanto eu gostaria / Eu não sei do meu passado / Nem minha genealogia / Mas carrego algumas pistas [...] / E na pele a cor bem preta / Girando uma carrapeta / De histórias instigantes (ARRAES, 2017, p. 32).

Nos versos, aparecem traços de identidade étnico-racial misturados à resistência que se relaciona com o que Foucault chamou de "[...] insurreição de saberes dominados, que são os conteúdos históricos e os saberes ingênuos [...]" (FOUCAULT, 2007, p. 170). Para ele,

[...] os saberes dominados são estes blocos de saber histórico que estavam presentes e mascarados no interior dos conjuntos funcionais e sistemáticos e que a crítica pode fazer reaparecer, evidentemente através do instrumento de erudição [...] (FOUCAULT, 2007, p. 170).

Zilá Bernd (1987) pensa o conceito de identidade como um processo associado ao conceito de alteridade, na dinâmica da construção e desconstrução da identidade na relação com a diferença. "Esta consciência da diferença para o negro brasileiro é o elemento sobre o qual se funda um projeto de superação da sua marginalidade histórica" (BERND, 1987, p. 38). Arraes traz à tona em seu texto, a questão identitária por meio da inserção do corpo negro como diferença, revestindo-o de positividade tanto no campo estético como comportamental. O corpo que a tradição ocidental desenhou como apropriado apenas para o trabalho, o corpo convencionalmente representado como depositário de qualidades e sentidos negativos e desprestigiados. A autora reinscreve a diferença como signo da individualidade: "Eu não sei de onde veio / Meu cabelo enrolado / Minha cor escurecida / Ou nariz nesse formato / Mas a força ancestral / Se mostrou a maioral". 
Conforme afirma Lima (2006), “a literatura é um espaço não apenas de representação neutra, mas de enredos e lógicas, onde ao me representar eu me recrio e ao me recriar eu me represento". Em "Origem", o eu-lírico, ao reconhecer suas origens, abre o caminho para a libertação das imposições eurocêntricas que ao longo dos anos vividos faz parte do imaginário da sociedade deste país. Assim, constrói um presente afrobrasileiro a partir do conhecimento do passado africano:

É que meus antepassados / Precisavam de juntar / Uma gente descendente / Para se fazer lutar / Relembrando nossa história / Conquistando essa memória / Que tentaram se apagar. / O meu povo batalhou/Hoje sou sobrevivente / Sou herança dessa gente / Que por mim só guerreou/ Sobre mim foi derramada / Essa importante missão / De crescer a identidade / Do meu povo na nação / E com fala flamejante / Com coragem incessante / Feito um bruto furacão (ARRAES, 2017, p. 32).

A escritora apropria-se da palavra para (re)contar o passado histórico de seu povo. A poesia de Arraes, nesse sentido, torna-se espaço de ricas possibilidades simbólicas, que podem se lançar como discursos alternativos, contribuindo para desmantelar uma História tradicional "formada por brancos, privilegiados, ocidentais e masculinos, muitos dos quais dominados por pressupostos patriarcais, brancos e burgueses" (CHANTER, 2011, p. 13), lançando-se a diferentes perspectivas, pela inclusão da "voz" e das representações de minorias sociais

visto que - isto a história não cansa de nos ensinar - o discurso não é simplesmente aquilo que traduz as lutas ou os sistemas de dominação, mas é aquilo porque, pelo que se luta, o poder do qual nós queremos apoderar (FOUCAULT, 2007, p. 10). 
São configuradas formações discursivas, no poema "Origem”, em que a voz literária negra e feminina é destituída de submissão "Sobre mim foi derramada / Essa importante missão / De crescer a identidade / Do meu povo na nação". Ao contrário, a poeta apropria-se da escrita para criar um universo em que toma para si a continuidade da luta contra a hegemonia racial. Arraes imprime em sua escrita a marca da especificidade da condição do ser negro, saindo da posição de negro como vítima e assumindo a posição de sujeito e de compromisso com a questão. De acordo com Bernd:

A literatura negra brasileira configura-se como literatura de resistência, ou seja, a que constrói com a matéria da cultura africana que sobreviveu na América em presença da cultura europeia e indígena. A literatura utiliza o aporte desta cultura resistente em uma produção que servirá para singularizar um grupo, fornecendo-lhes mitos, símbolos e valores, em suma, elementos que permitem a emergência de uma imagem positiva de si próprios (1987, p. 86).

A "fala flamejante com coragem incessante" se traduz nas palavras da própria autora, marcada pelo seu posicionamento político/ideológico:

Me considero tão representante da luta negra e feminista quanto todas as outras mulheres negras que resistem diariamente, cada uma no seu contexto de vida, nas mais diversas profissões. [...] tenho sempre em mente que há um compromisso da minha parte e me esforço para ampliar as vozes de outras pessoas que devem ser ouvidas. [...] tudo o que desejo fazer é um pouco de diferença na sociedade, ajudar a despertar questionamentos incômodos e auxiliar na conscientização de mais pessoas. Porque tudo isso diz respeito a grupos de pessoas, são fatos sociais, são questões importantes para mim e para muitas outras mulheres (ARRAES, 2015). 
No poema "Desequilíbrio", "Pra cada preta ferida / Um quilombo inteiro / Nascido e fortalecido / No útero dessa mátria", Arraes se apropria das palavras partindo de um universo sociocultural inserido em circuitos e organizações afins à literatura afrofeminina, que, segundo Ana Rita Santiago (2012), estão “imbuídas de tensão e circunstanciados por construções socioculturais". Para Santiago (2016):

a produção literária de escritoras negras contemporâneas pode minar processos de coisificação, a que foram reduzidas personagens negras femininas na literatura brasileira, pois vozes se erguem, perspicaz e agudamente, contra estereótipos, estigmas, discriminação e visões exóticas, colonialistas que ainda passeiam em trânsitos literários. Para tanto, conciliam e opõem igualmente quando necessário, o passado histórico e o presente, bem como pontos culturais africanos tradicionais como aqueles hoje ressignificados no Brasil (p. 20).

O eu poético em "Desequilíbrio" tece uma narrativa de si, mas ligada a memórias coletivas que se estendem às histórias coletivas de outras mulheres e personagens negras, aqui caracterizadas por "Pra cada preta ferida". A noção de uma escrita de si e, por consequência, nós é visível no texto de Arraes, vislumbrando possibilidades de pensar sobre si, tornando a escrita um entrecruzamento entre uma função poética, política e histórica.

Nota-se, no poema, registro da violência simbólica pela condição de gênero e raça. Na contramão da produção colonial, na qual, segundo Spivak, "o sujeito subalterno feminino está ainda mais profundamente na obscuridade", Arraes dá voz e junta as marcas deixadas por rastros ancestrais, instalados a partir do caos da escravidão. O eulírico é sujeito atuante que não se torna imobilizado perante a adversidade "Um quilombo inteiro / Nascido e fortalecido', mostra que é preciso ter coragem e resiliência para o 
exercício pleno da cidadania: "No útero dessa mátria". A busca pela emancipação, portanto, faz-se presente nos versos de Arraes. A escrita dela traz em seu bojo questões sociais que revelam marcas identitárias de mulheres negras.

\section{Conclusões possíveis}

Recuperar fatos históricos e reelaborá-los por meio da literatura continua sendo uma prática recorrente e profícua, pois possibilita percorrer os espaços de sombra, engendrados por uma História que silenciou e marginalizou inúmeros acontecimentos e sujeitos sociais. A literatura possibilita novos caminhos, multiplica perspectivas que compõem o entendimento que tecemos diante dos acontecimentos do passado e do presente - e torna-se, então, um espaço de elasticidade no qual a História se atualiza e se (re)constrói.

A História (re)construída na poética de Jarid Arraes se ampara longe das amarras convencionais que compactam o pensamento em direção ao entendimento da realidade segundo as representações dos discursos oficiais, pois “[...] para compreender um discurso devemos perguntar sistematicamente o que ele cala" (ORLANDI, 1997, p. 160). E, nesse estudo em particular, o olhar diferenciado advém da posição marginalizada vivida pela autora e sua ancestralidade, o que as proporciona uma experiência diferente face ao mundo, e que, justamente por isso, tem condições de lançar uma nova perspectiva sobre os discursos misóginos e patriarcais. Os poemas "Origem" e "Desequilíbrio" mesmo ligando-se a realidade, "desliga-se" dela ao propor uma nova possibilidade de representação da História oficial, a contrapelo da razão instrumental, na contramão dos discursos da ordem e do poder. Por isso, não deixamos de considerar o caráter histórico 
de sua representação literária, as raízes que mantém com o social na crítica em relação a um discurso histórico dominante e colonizador; marcadamente branco, europeu e masculino. O que essa literatura absorvida pelo olhar da mulher provoca é o deslocamento da perspectiva hegemônica da História. Por isso, mesmo mantendo sua relação com a realidade social e com os relatos cristalizados da História oficial, o faz refutando sua total legitimidade, para trazer à luz novas vozes: as das mulheres.

Ao falar de Literatura, colocamos em questão as veredas do imaginário, percorridas para dar vida ao "[...] abstrato, o não-visto e não-experimentado. É elemento organizador do mundo, que dá coerência, legitimidade e identidade" (PESAVENTO, 2006, p. 2). Ou seja, pela e na Literatura é possível percorrer caminhos nunca pisados, (re)significar criativamente o que está fragilizado, o que ficou por muito tempo, esquecido, subjugado, como é o caso da História das mulheres negras no Brasil.

A análise dos textos de Jarid Arraes permite (re)criar o passado e projetá-lo para o presente em suas inúmeras possibilidades, num movimento contrário aos discursos aprisionados nos limite da ordem e do poder eurocêntrico, patriarcal e moralizante. Notase, portanto, que essa recuperação histórica tem um apelo à construção de uma identidade brasileira fundada no pertencimento de um povo, em um passado comum e na (des)construção de uma identidade feminina essencialista. À volta ao passado histórico para reconstruir uma identidade fortemente baseada na concepção de miscigenação étnica e cultural reconstrói, ao mesmo tempo, as múltiplas subjetividades femininas que comportam uma história de mais de 500 anos.

\section{Referências}


ARRAES, Jarid. Origem. Revista Parênteses. Disponível em:

<http://www.revistaparenteses.com.br/project/edicao-especial-04/>. Acesso em: 8 abr. 2018.

Cordelista e feminista: protesto contra a opressão. Entrevista concedida a Natacha Cortêz. Revista TPM. São Paulo, 19 fev. 2015. Disponível em:

<http://revistatrip.uol.com.br/tpm/cordelista-e-feminista-conheca-jarid-arraes-uma-vozde-protesto-contra-a-opressao>. Acesso em: 11 jan. 2017.

BERND, Zilá. Negritude e literatura na América Latina. Porto Alegre: Mercado Aberto, 1987.

CERTEAU, Michel de. A escrita da história. 2 ed. Tradução de Maria de Lourdes Menezes. Rio de Janeiro: Forense Universitária, 2006.

CHANTER, Tina. Gênero: conceitos-chave em filosofia. Trad. Vinicius Figueira. Porto Alegre: ArtMed, 2011.

FOUCAULT, Michel. As palavras e as coisas. São Paulo: Martins Fontes, 2007.

LEONARDI, Victor. Jazz em Jerusalém: inventividade e tradição na história cultural. São Paulo. Nankin Editorial, 1999.

LIMA, Luiz Costa. História. Fiç̧ão. Literatura. São Paulo: Companhia das Letras, 2006. LIMA, Diane. Do Juazeiro do Norte, é Jarid Arraes a escritora que nos representa. No Brasil. 9 jun. 2015. Disponível em: <http://nobrasil.co/do-juazeiro-do-norte-e-jaridarraes-a-escritora-que-nos-representa/>. Acesso em: 10 jan. 2017.

MALLARD, L. et. al. História Literatura: ensaios. Campinas: Ed. Unicamp: 1995.

PESAVENTO, Sandra Jatahy. História e literatura: uma velha-nova história. Nuevo Mundo Mundos Nuevos. Debates, 28 jan. 2006. Disponível em:

<http:/nuevomundo.revues.org/index1560.html>. Acesso em: 10 ago. 2012.

SANTIAGO, Ana Rita. Vozes literárias de autoras negras. Disponível em: <http://www.youblisher.com/p/936362-VOZES-LITERARIAS-DE-ESCRITORAS-NEGRASANA-RITA-SANTIAGO-UFRS/>. Acesso em: 12 fev. 2017. 
SPIVAK, Gayatri Chakravorty. Pode o subalterno falar? Tradução de Sandra Regina Goulart Almeida, Marcos Pereira Feitosa e André Pereira Feitosa. Belo Horizonte: UFMG, 2010.

\footnotetext{
' Essa expressão faz referência aos estudos desenvolvidos por Luiz Costa Lima (2006) no livro: História, Fiç̧ão e Literatura.
}

Recebido em 12 de janeiro de 2018. Aceito em 28 de fevereiro de 2018. 